\title{
Uso de plantas medicinais por idosos da atenção primária
}

\author{
Laura Ligiana Dias Szerwieski ${ }^{1}$, Diógenes Aparício Garcia Cortez ${ }^{2}$, Rose Mari Bennemann ${ }^{3}$, \\ Eraldo Schunk Silva ${ }^{4}$, Lucia Elaine Ranieri Cortez ${ }^{5}$
}

\footnotetext{
${ }^{1}$ Enfermeira, Mestre em Promoção da Saúde. Maringá, PR, Brasil. E-mail: laura.enfer@gmail.com.

${ }^{2}$ Farmacêutico. Doutor em Química. Docente do Centro Universitário Maringá. Maringá, PR, Brasil. E-mail: dagcortezz@gmail.com.

${ }^{3}$ Nutricionista, Doutora em Saúde Pública. Docente do Centro Universitário de Maringá. Maringá, PR, Brasil. Email:rose.bennemann@gmail.com.

${ }^{4}$ Estatístico, Doutor em Agronomia. Professor Adjunto da Universidade Estadual de Maringá. Maringá, PR, Brasil. Email: eraldoschunk@gmail.com.

${ }^{5}$ Farmacêutica, Doutora em Química de Produtos Naturais. Docente do Centro Universitário de Maringá. Maringá, PR, Brasil. E-mail: lucia.cortez@unicesumar.edu.br.
}

Recebido: 24/06/2016.

Aceito: 30/11/2016.

Publicado: 17/04/2017.

\section{Como citar esse artigo}

Szerwieski LLD, Cortez DAG, Bennemann RM, Silva ES, Cortez LER. Uso de plantas medicinais por idosos da atenção primária. Rev. Eletr. Enf. [Internet]. 2017 [acesso em: ____;19:a04. Disponível em: http://dx.doi.org/10.5216/ree.v19.42009.

\section{RESUMO}

Este estudo tem como objetivo verificar o uso de plantas medicinais por idosos usuários da atenção primária. Caracterizou-se como um estudo transversal, correlacional, analítico e descritivo, com abordagem quantitativa. Realizado no oeste do Paraná, em 2016. Foram aplicados 252 questionários aos idosos, contendo informações sociodemográficas e questões relacionadas ao uso de plantas medicinais. Os resultados evidenciaram que $72,22 \%$ dos idosos utilizam plantas, entre as mais citadas destacam-se a Hortelã, Cidreira, Boldo e Alecrim. Referem utilizar por ser melhor para curar, gostam mais e não faz mal. Dado discordante quanto às indicações, sendo que $36,81 \%$ não indicam por medo de causar malefício. Quanto à toxicidade relataram efeitos adversos que não são apresentados por literatura científica. Ressalta-se a importância de uma orientação correta quanto à toxicidades de algumas plantas, bem como seus benefícios, e a importância do enfermeiro neste contexto já que atua como um promotor da saúde.

Descritores: Enfermagem; Assistência a Idosos; Plantas Medicinais; Atenção Primária à Saúde.

\section{INTRODUÇÃO}

O uso de plantas medicinais sempre fez parte da história da humanidade, desde os primórdios as civilizações perceberam que algumas plantas poderiam auxiliar no combate as doenças e revelaram empiricamente seu poder curativo ${ }^{(1-2)}$.

A prática do uso de plantas medicinais traz significados que foram construídos através das relações familiares, em que os mais velhos aprenderam sobre o uso destas com seus ascendentes, principalmente 
mães e avós que desempenhavam o papel de cuidadoras. A aquisição dos saberes foi transmitida entre gerações, sendo os idosos considerados as pessoas mais sábias que partilhavam seus conhecimentos com os mais jovens ${ }^{(3)}$.

Dentro desse cenário de cuidado percebe-se a utilização de práticas complementares voltadas à saúde, com plantas medicinais empregadas para aliviar ou mesmo curar algumas enfermidades ${ }^{(1-2)}$. Assim, o Ministério da Saúde instituiu o Programa Nacional de Plantas Medicinais e Fitoterápicos que objetiva "garantir à população brasileira o acesso seguro e o uso racional de plantas medicinais e fitoterápicos"(4), ajudando a fortalecer o uso de plantas medicinais no cotidiano das pessoas.

Entre os profissionais que atuam na rede de cuidados, a enfermagem integra o conhecimento científico com a realização de procedimentos técnicos e os cuidados alternativos, permitindo o cuidado multidimensional, humanizado e integral, atuando na prevenção de agravos e na promoção e recuperação da saúde, especialmente na atenção primária ${ }^{(5)}$. Desse modo, reconhecendo a importância do enfermeiro como promotor da saúde, o Conselho Regional de Enfermagem de Santa Catarina foi um dos precursores a considerar legítima a prescrição de plantas medicinais na forma de chás (rasurada, seca, in natura) para uso de tratamento clínico pelo enfermeiro fitoterapeuta, desde que este esteja devidamente habilitado, com titulação em Terapia Alternativa conforme protocolo terapêutico das secretarias municipais de saúde ${ }^{(6)}$.

A partir dessas políticas, pesquisas foram incentivadas para promover o uso correto das plantas medicinais. Porém ainda existe uma carência de estudos voltados para esta temática, sendo necessário saber se as plantas utilizadas pelos idosos estão coincidentes com as indicações terapêuticas apresentadas nas pesquisas científicas, se os usuários conhecem os efeitos colaterais que as mesmas podem causar, e também para auxiliar a equipe de saúde a incorporar o uso de plantas como um recurso terapêutico ${ }^{(7)}$. Desse modo, este estudo tem como objetivo verificar o uso de plantas medicinais por idosos usuários da atenção primária.

\section{MÉTODOS}

Esta pesquisa caracterizou-se como um estudo transversal, correlacional, analítico e descritivo, com abordagem quantitativa. Realizado no município de Itaipulândia (PR), no ano de 2016. Possui uma população estimada de 10.000 habitantes e apresenta $12 \%$ de idosos, transcendendo as taxas esperadas no Brasil ${ }^{(8)}$. Possui quatro unidades básicas de saúde que prestam o atendimento desde o lactente até o idoso, sendo uma central e três periféricas, todas constituídas por uma equipe multiprofissional com enfermeiros, nutricionistas, odontólogos, médicos e agentes comunitários de saúde. Em média, o município atende 250 idosos por semana em consultas periódicas, bem como, atendimentos para as especialidades, orientações quanto ao uso de medicações e realização de procedimentos.

Inicialmente foi realizado um levantamento do estudo, sendo observado o número de idosos acompanhados pela atenção primária $(n=754)$, em seguida foi definido por meio de cálculo estatístico que na Unidade Central seria realizado uma amostra por meio de sorteio aleatório, devido ter um número maior de pessoas, e nas periféricas por conveniência, por causa da dificuldade na coleta dos dados. $\mathrm{O}$ cálculo da 
amostra assumiu nível de confiança de $95 \%$, margem de erro de $5 \%$, com base em cálculos realizados no Software Statistica 8.4.

Assim, esta pesquisa estabeleceu como critério de inclusão ser idoso, residente no meio urbano, cadastrado no sistema E-SUS e estar sendo acompanhado pelas Unidades Básicas de Saúde. Foram excluídas as pessoas com idade menor do que 60 anos, e aquelas com idade acima desta que apresentam deficiências sensoriais (surdez e/ou mudez).

As entrevistas para coleta de dados foram realizadas na residência habitual dos idosos (domicílios ou lar dos idosos), no período de fevereiro a abril de 2016. A pesquisadora principal identificou o idoso elegível para o estudo, seguido de uma abordagem inicial, explicando os objetivos da pesquisa. Em caso de aceite foi assinado o Termo de Consentimento Livre e Esclarecido, e aplicado o questionário semiestruturado contendo informações sociodemográficas (sexo, idade, estado civil, escolaridade, atividade econômica) e questões relacionadas às plantas medicinais (uso, local de aquisição, indicação, frequência, toxicidade, motivo de uso e modo de preparo). As espécies são muito conhecidas da medicina popular e suas identificações taxonômicas das plantas medicinais foram por comparação com as espécies do herbário da Unipar (PR).

Os dados obtidos foram digitados no Microsoft Excel 2010 e analisados estatisticamente com o auxílio do Software Statistica 8.4. Para as variáveis quantitativas foram utilizadas tabelas de frequências com percentual e tabelas de contingência com a utilização do Teste Exato de Fisher e Qui quadrado para verificar possíveis associações significativas entre as variáveis de interesse. Foi adotado um nível de significância de $5 \%$, ou seja, foram consideradas significativas as associações cujo $p<0,05$.

O estudo respeitou as normas nacionais e internacionais regulamentadoras de pesquisas envolvendo seres humanos, seguindo a Resolução 466/2012 do Conselho Nacional de Saúde, sendo aprovado pelo Comitê de Ética em Pesquisa do Centro Universitário de Maringá-Unicesumar, sob n 1.401 .270 em 03 de fevereiro de 2016.

\section{RESULTADOS}

Foram entrevistados 252 idosos, desse total $72,22 \%$ ( $n=182$ ) fazem uso de plantas medicinais, sendo 67,58\% ( $n=123)$ do sexo feminino. Em relação à idade, 51,65\% ( $n=94)$ referiram estar na faixa etária de 6069 anos, 36,26\% ( $n=66)$ de 70 a 79 anos, e 12,09\% ( $n=22)$ com idade igual ou acima de 80 anos. Ao ser observado a escolaridade, $51,65 \%$ ( $n=94)$ dos participantes não são alfabetizados e $38,46 \%(n=70)$ possuem de um a quatro anos de estudo.

Foi verificada uma diferença significativa quanto ao uso de plantas medicinais em relação ao sexo $\left(0,0043^{*}\right)$, sendo que as mulheres referiram utilizar mais plantas medicinais do que os homens. Ao ser observado a escolaridade, os analfabetos ou que possuem de um a quatro anos de estudo utilizam mais plantas medicinais do que os outros $(0,0091 *)$. Quanto à ocupação, $83,52 \%$ são inativos economicamente ( $n=152)$ e $16,48 \%$ possuem atividade com remuneração $(n=30)$. A renda mensal de $33(18,13 \%)$ idosos não atinge um salário mínimo, já a maior parte destes ( $n=144,79,12 \%)$ recebem um salário mínimo. Esses dados 
são apresentados na Tabela 1.

Tabela 1: Relação entre o uso de plantas e dados sociodemográficos. Itaipulândia, PR, Brasil, 2016.

\begin{tabular}{|c|c|c|c|}
\hline \multirow{2}{*}{ Perfil } & \multicolumn{2}{|c|}{ Plantas medicinais } & \multirow{2}{*}{ Teste Exato de Fisher p-valo } \\
\hline & $\operatorname{Sim} n(\%)$ & Não n(\%) & \\
\hline \multicolumn{4}{|l|}{ Gênero } \\
\hline Mulheres & $123(67,58)$ & $35(50,00)$ & \multirow[t]{2}{*}{$0,0043^{*}$} \\
\hline Homens & $59(32,42$ & $35(50,00)$ & \\
\hline \multicolumn{4}{|l|}{ Idade (anos) } \\
\hline $60-69$ & $94(51,65)$ & $33(47,14)$ & \multirow{3}{*}{0,4765} \\
\hline $70-79$ & $66(36,26)$ & $31(44,29)$ & \\
\hline 80 ou + & $22(12,09)$ & $6(8,57)$ & \\
\hline \multicolumn{4}{|l|}{ Escolaridade } \\
\hline Não alfabetizado ou analfabeto & $94(51,65)$ & $23(32,86)$ & \multirow{4}{*}{$0,0091 *$} \\
\hline 1 a 4 anos de estudos & $70(38,46)$ & $42(60,00)$ & \\
\hline 5 a 8 anos de estudos & $4(5,71)$ & $17(9,34)$ & \\
\hline 9 a 11 anos de estudos & $1(0,55)$ & $1(1,43)$ & \\
\hline \multicolumn{4}{|l|}{ Ocupação } \\
\hline Ativo & $30(16,48)$ & $7(10,00)$ & \multirow[t]{2}{*}{0,2356} \\
\hline Inativo & $152(83,52)$ & $63(90,00)$ & \\
\hline \multicolumn{4}{|l|}{ Renda mensal (salários mínimos) } \\
\hline$<1 \mathrm{sm}$. & $33(18,13)$ & $6(8,57)$ & \multirow{3}{*}{0,1225} \\
\hline $1 \mathrm{sm}$. & $144(79,12)$ & $61(87,14)$ & \\
\hline 2 a $3 \mathrm{sm}$. & $5(2,75)$ & $3(4,29)$ & \\
\hline
\end{tabular}

A Tabela 2 apresenta o uso de plantas medicinais por Unidades Básicas de Saúde, sendo a Unidade central representada por (UBS A) e as periféricas por (UBS B, C, D).

Analisando o uso de plantas por unidade de saúde é verificado diferenças estatisticamente significativas quanto ao seu uso $\left(p=0,0017^{*}\right)$, sendo que todas as Unidades apresentaram uma porcentagem elevada de pessoas que referem o uso de plantas. Quanto ao modo de preparo também ocorreu diferença significativa $\left(p=0,0001^{*}\right)$, sendo a infusão a mais citada pelas UBS.

Com relação ao local de aquisição das plantas, $93,40 \%(n=170)$ dos idosos colhem no próprio quintal e hortas, seguido de $12,63 \%$ ( $n=23)$ nos vizinhos, e 11,53\% ( $n=21)$ em outros locais como farmácias, mercados, raizeiros e outros. 
Tabela 2: Caracterização do uso de plantas por Unidade Básica de Saúde. Itaipulândia, PR, Brasil, 2016.

\begin{tabular}{|c|c|c|c|c|c|c|}
\hline & UBS(A) & UBS(B) & UBS(C) & UBS(D) & \multirow{2}{*}{ Qui quadrado } & \multirow{2}{*}{ p-valor } \\
\hline & $n(\%)$ & $n(\%)$ & $n(\%)$ & $n(\%)$ & & \\
\hline \multicolumn{7}{|c|}{ Uso de planta medicinal } \\
\hline Não & $23(46,00)$ & $8(13,79)$ & $12(21,82)$ & $27(30,34)$ & \multirow{3}{*}{15,1941} & \multirow{3}{*}{$0,0017^{*}$} \\
\hline Sim & $27(54,00)$ & $50(86,21)$ & $43(78,18)$ & $62(69,66)$ & & \\
\hline Total & $50(100,00)$ & $58(100,00)$ & $55(100,00)$ & $89(100,00)$ & & \\
\hline \multicolumn{7}{|l|}{ Local de aquisição } \\
\hline Quintal & $26(89,66)$ & $43(71,67)$ & $39(75,00)$ & $62(84,93)$ & \multirow{4}{*}{89,417} & \multirow{4}{*}{0,1769} \\
\hline Vizinhos & $1(3,45)$ & $11(18,33)$ & $5(9,62)$ & $6(8,22)$ & & \\
\hline Outros & $2(6,90)$ & $6(10,00)$ & $8(15,38)$ & $5(6,85)$ & & \\
\hline Total & $29(100,00)$ & $60(100,00)$ & $52(100,00)$ & $73(100,00)$ & & \\
\hline \multicolumn{7}{|l|}{ Indica o uso plantas } \\
\hline Não & $23(46,00)$ & $11(24,44)$ & $21(33,87)$ & $12(44,44)$ & \multirow{3}{*}{56,940} & \multirow{3}{*}{0,1275} \\
\hline $\operatorname{Sim}$ & $27(54,00)$ & $34(75,56)$ & $41(66,13)$ & $15(55,56)$ & & \\
\hline Total & $50(100,00)$ & $45(100,00)$ & $62(100,00)$ & $27(100,00)$ & & \\
\hline \multicolumn{7}{|l|}{ Frequência } \\
\hline Diariamente & $14(23,33)$ & $8(29,63)$ & $15(33,33)$ & $15(35,71)$ & \multirow{4}{*}{39,542} & \multirow{4}{*}{0,6829} \\
\hline $1 \mathrm{x}$ semana & $13(21,67)$ & $7(25,93)$ & $12(26,67)$ & $7(16,67)$ & & \\
\hline $3 x$ semana & $33(55,00)$ & $12(44,44)$ & $18(40,00)$ & $20(47,62)$ & & \\
\hline Total & $60(100,00)$ & $27(100,00)$ & $45(100,00)$ & $42(100,00)$ & & \\
\hline \multicolumn{7}{|l|}{ Motivo } \\
\hline Promove a cura & $27(38,03)$ & $31(50,82)$ & $49(45,37)$ & $20(58,82)$ & \multirow{4}{*}{99,191} & \multirow{4}{*}{0,1281} \\
\hline Gosta mais & $21(29,58)$ & $10(16,39)$ & $20(18,52)$ & $9(26,47)$ & & \\
\hline Não faz mal & $23(32,39)$ & $20(32,79)$ & $39(36,11)$ & $5(14,71)$ & & \\
\hline Total & $71(100,00)$ & $61(100,00)$ & $108(100,00)$ & $34(100,00)$ & & \\
\hline \multicolumn{7}{|l|}{ Modo de preparo } \\
\hline Infusão & $27(96,43)$ & $33(42,86)$ & $34(64,15)$ & $42(40,00)$ & \multirow{4}{*}{37,629} & \multirow{4}{*}{$0,0001^{*}$} \\
\hline Maceração & $0(0,00)$ & $16(20,78)$ & $12(22,64)$ & $30(28,57)$ & & \\
\hline Outros & $1(3,57)$ & $28(36,36)$ & $7(13,21)$ & $33(31,43)$ & & \\
\hline Total & $28(100,00)$ & $77(100,00)$ & $53(100,00)$ & $105(100,00)$ & & \\
\hline
\end{tabular}

* Significativo ao nível de confiança de $95 \%$

O principal modo de preparo foi a infusão com $74,72 \%$ ( $n=136)$, utilizado três vezes na semana $(42,85 \%, n=78)$. Quanto ao motivo de uso, $69,78 \%(n=127)$ dos idosos acham melhor para curar, $47,80 \%$ ( $n=87)$ usam por não fazer mal a saúde e $32,96 \%(n=60)$ por gostarem mais.

Quanto à indicação a outras pessoas, $69,78 \%(n=127)$ indicam o uso de plantas, enquanto que $36,81 \%$ ( $n=67)$ não indicam por medo de causar malefício. Já em relação à toxicidade, $87,36 \%$ ( $n=159)$ dos idosos não sentiram nenhum efeito colateral após o uso, porém $12,6 \%(n=23)$ assinalaram no questionário que algumas plantas como Cidreira, Guaco, folha de Laranja e Alecrim podem causar batedeira no coração, a Cidreira e Chuchu podem diminuir muito a pressão e fazem mal para o fígado, enquanto que Taioá, Chapéu de coro e folha de Goiaba podem causar forte dor no estomago, e o Hortelã aumenta o açúcar no sangue.

No que se refere às principais plantas medicinais utilizadas, $11,22 \%$ dos idosos relataram Hortelã ( $n=123), 11,13 \%$ Cidreira ( $n=122), 9,03 \%$ Boldo ( $n=99), 6,84 \%$ Alecrim ( $n=75), 6,84 \%$ Erva-doce $(n=75), 6,20 \%$ Arruda ( $n=68), 5,93 \%$ Chuchu ( $n=65), 5,66 \%$ Camomila $(n=62), 4,93 \%$ Melissa $(n=54), 4,38 \%$ Guaco $(n=48)$, $2,83 \%$ Losna $(n=31)$, entre outras. Quanto à finalidade e parte utilizada, os resultados encontrados apresentam semelhanças com a literatura consultada (Tabela 3). 
Tabela 3: Principais plantas medicinais mencionadas, família, espécie, uso, parte utilizada. Itaipulândia, PR, Brasil, 2016.

\begin{tabular}{|c|c|c|c|c|c|c|}
\hline $\begin{array}{c}\text { Planta } \\
\text { medicinal }\end{array}$ & Família & Espécie & $\begin{array}{c}\text { Uso } \\
\text { mencionado } \\
\text { pelos idosos }\end{array}$ & $\begin{array}{l}\text { Uso mencionado na } \\
\text { literatura }\end{array}$ & $\begin{array}{l}\text { Parte } \\
\text { utilizada }\end{array}$ & Total N(\%) \\
\hline Hortelã & Lamiaceae & Mentha piperita L. & $\begin{array}{l}\text { Gripe, má } \\
\text { digestão, } \\
\text { vermes }\end{array}$ & Digestivo, Antisséptico ${ }^{(9)}$ & Folhas & $123(11,22)$ \\
\hline Cidreira & Gramineae & $\begin{array}{l}\text { Cymbopogon citratus } \\
\text { (DC) Stapf }\end{array}$ & Calmante & $\begin{array}{l}\text { Antiespasmódico, } \\
\text { ansiolítico e sedativo leve } \\
\text { (9) }\end{array}$ & Folhas & $122(11,13)$ \\
\hline Boldo & Monimiaceae & $\begin{array}{l}\text { Plectranthusbarbatus } \\
\text { Andr. }\end{array}$ & Má digestão & Digestivo $^{(9-10)}$ & Folhas & $99(9,03)$ \\
\hline Alecrim & Laminaceae & $\begin{array}{c}\text { Rosmarinus officinalis } \\
\text { L. }\end{array}$ & $\begin{array}{l}\text { Problema no } \\
\text { estômago }\end{array}$ & Distúrbios intestinais $^{(9)}$ & Folhas & $75(6,84)$ \\
\hline Erva-doce & Apiaceae & $\begin{array}{l}\text { Foeniculum vulgare } \\
\text { Mill }\end{array}$ & $\begin{array}{c}\text { Gases, } \\
\text { digestão }\end{array}$ & $\begin{array}{c}\text { Bronquite, tosse, dispepsia, } \\
\text { flatulência }^{(9)}\end{array}$ & Semente & $75(6,84)$ \\
\hline Arruda & Rutaceae & Ruta graveolens $\mathrm{L}$. & Gases & $\begin{array}{c}\text { Carminativa, } \\
\text { antiespasmódica }\end{array}$ & Folhas & $68(6,20)$ \\
\hline Chuchu & Cucurbitaceae & Sechium edule (Jacq.) S & Pressão alta & Hipertensão ${ }^{(9)}$ & Folhas/fruto & $65(5,93)$ \\
\hline Camomila & Asteraceae & $\begin{array}{c}\text { Matricaria chamomilla } \\
\text { L. }\end{array}$ & Calmante & $\begin{array}{c}\text { Ansiedade, insônia, } \\
\text { dispepsia, flatulência }{ }^{(9-10)}\end{array}$ & Folhas & $62(5,66)$ \\
\hline Melissa & Lamiaceae & Melissa officinalis $L$. & Calmante & $\begin{array}{l}\text { Antiespasmódico, } \\
\text { ansiolítico e sedativo leve }{ }^{(9)}\end{array}$ & Folhas & $54(4,93)$ \\
\hline Guaco & Asteraceae & $\begin{array}{l}\text { Mikania glomerata } \\
\text { Sprengel }\end{array}$ & $\begin{array}{l}\text { Gripe, } \\
\text { Resfriados }\end{array}$ & $\begin{array}{l}\text { Prevenção e tratamento da } \\
\text { asma, broncodilatador, } \\
\text { antisséptico das vias } \\
\text { respiratórias }^{(9)}\end{array}$ & Folhas & $48(4,38)$ \\
\hline Losna & Asteraceae & Artemisia absinthium L. & $\begin{array}{l}\text { Dor no } \\
\text { estômago }\end{array}$ & Dispepsia ${ }^{(9)}$ & Folhas & $31(2,83)$ \\
\hline Marcela & Asteraceae & $\begin{array}{c}\text { Achyrocline } \\
\text { satureioides (Lam.) }\end{array}$ & Digestão & $\begin{array}{l}\text { Antidispéptico, } \\
\text { antiespasmódico e anti- } \\
\text { inflamatório }^{(9)}\end{array}$ & Flor & $18(1,64)$ \\
\hline Carqueja & Asteraceae & $\begin{array}{l}\text { Baccharis trimera } \\
\text { (Less) DC. }\end{array}$ & $\begin{array}{l}\text { Melhora a } \\
\text { digestão }\end{array}$ & $\begin{array}{l}\text { Doenças do fígado, } \\
\text { estômago e intestinos }\end{array}$ & Folhas & $18(1,64)$ \\
\hline Ponta-alívio & Asteraceae & Achillea millefolium L. & $\begin{array}{l}\text { Dor no } \\
\text { estômago, } \\
\text { cólica }\end{array}$ & $\begin{array}{l}\text { Aperiente, antidispéptico, } \\
\text { anti-inflamatório e } \\
\text { antiespasmódico }^{(9)}\end{array}$ & Folhas & $17(1,55)$ \\
\hline Manjerona & Lamiaceae & Origanum majorana L. & $\begin{array}{l}\text { Melhora a } \\
\text { digestão }\end{array}$ & Digestivo $^{(9)}$ & Folhas & $16(1,46)$ \\
\hline Poejo & Lamiaceae & Mentha pulegium & $\begin{array}{l}\text { Gripe, } \\
\text { problema } \\
\text { intestinal }\end{array}$ & $\begin{array}{l}\text { Antioxidante, anti- } \\
\text { hiperglicêmico, } \\
\text { antiinflamatório, } \\
\text { antimicrobiano }^{(11)}\end{array}$ & Folhas & $11(1,00)$ \\
\hline $\begin{array}{l}\text { Espinheira- } \\
\text { santa }\end{array}$ & Celastraceae & $\begin{array}{l}\text { Maytenus ilicifolia } \\
\text { (Schrad.) Planch. }\end{array}$ & $\begin{array}{l}\text { Melhora a } \\
\text { digestão }\end{array}$ & Digestivo $^{(9-10)}$ & Folhas & $10(0,91)$ \\
\hline $\begin{array}{l}\text { Quebra } \\
\text { pedra }\end{array}$ & Euphorbiaceae & Phyllanthus niruri L. & Pedra nos rins & Litolítico $^{(9)}$ & Folhas & $10(0,91)$ \\
\hline Malva & Malvaceae & Malva sylvestris $\mathrm{L}$. & Laxante & Antinflamatório; laxativo ${ }^{(9)}$ & Folhas/flores & $9(0,82)$ \\
\hline $\begin{array}{l}\text { Lima da } \\
\text { pérsia }\end{array}$ & Rutaceae & $\begin{array}{l}\text { Citrus aurantium L. } \\
\text { subsp. bergamia }\end{array}$ & $\begin{array}{l}\text { Melhora a } \\
\text { digestão }\end{array}$ & Digestivo $^{(9)}$ & Fruto & $11(1,00)$ \\
\hline
\end{tabular}

\section{DISCUSSÃO}

Os dados evidenciam o uso de plantas medicinais pela maioria dos idosos acompanhados pela atenção primária, porém destaca-se que 15 idosos não utilizam nenhum tipo de planta devido proibição médica ou por terem medo de reações adversas. Esse dado enfatizou que é primordial quebrar a resistência cultural 
frente ao cientificismo biomédico imposto pelo mundo contemporâneo ${ }^{(9,11)}$. Sendo extremamente necessária a capacitação quanto à prescrição de fitoterápicos e plantas medicinais, com informações acerca do uso seguro de plantas medicinais e incentivo a sua prática ${ }^{(12)}$. Buscando trazer o conhecimento detalhado aos médicos, a Anvisa publicou o Memento Terapêutico da Farmacopeia Brasileira que orienta os profissionais médicos para a prescrição de plantas medicinais. Esse documento apresenta a nomenclatura popular e a parte utilizada da planta, além de contraindicações, precauções de uso, efeitos adversos, interações medicamentosas, vias de administração e posologia, auxiliando assim na prescrição dessas plantas $^{(10)}$.

A enfermagem tem sido uma das áreas mais atuantes, talvez pelo fato de realizar um atendimento multidimensional, humanizado e integral, e por atuar como promotora da saúde ${ }^{(4-5,12)}$. 0 enfermeiro tem o papel de preparar a equipe multiprofissional para atender esses usuários e promover o uso de plantas. Isso pode ser realizado através de grupos de educação permanente, em que os médicos, farmacêuticos e os demais membros da equipe de saúde realizem a discussão de casos clínicos, buscando conhecer as possíveis interações entre plantas e medicamentos tradicionais, modo de preparo e dosagem correta de cada planta, desse modo toda a equipe estará apta a repassar as informações a esses idosos. Ao conhecerem a realidade podem pensar em estratégias voltadas para as necessidades específicas que aquela população apresenta ${ }^{(4-}$ 5).

No caso deste estudo houve o predomínio de idosos do sexo feminino, com baixa escolaridade, recebendo até um salário mínimo mensal e inativas economicamente. Esses dados corroboram com outros estudos realizados que afirmam que atualmente tem ocorrido a feminização do envelhecimento ${ }^{(13)}$, e que as mulheres têm desenvolvido ao longo da história da humanidade o papel de cuidadoras e aderiram ao cultivo e uso de plantas medicinais para minimizar e curar enfermidades ${ }^{(14)}$.

É visto em outros estudos também o predomínio do sexo feminino e os autores descreveram que essa trajetória do envelhecimento feminino foi marcada pela pouca escolarização, baixa inserção no mercado de trabalho formal, baixa qualificação profissional, assim a mulher se tornou responsável pelos afazeres domésticos, por cultivar plantas medicinais e cuidar dos parentes mais idosos e do esposo ${ }^{(13)}$.

Além disso, outro estudo destaca que os idosos apresentam baixa escolaridade devido à própria época e cultura que estavam inseridos e que apresentam o conhecimento empírico sobre plantas medicinais que foi passado entre as gerações ${ }^{(15)}$.

Quanto à renda, os dados encontrados coincidem com pesquisa realizada no sul do Brasil, observouse que $67,7 \%$ dos usuários apresentam renda de até um salário mínimo e meio. A inatividade econômica remete ao fato de que após a aposentadoria os idosos diminuem seus papéis na comunidade e acabam por manter suas atividades somente no domicílio ${ }^{(16)}$.

Ao conhecer o perfil dos idosos, é possível compreender que eles estão inseridos em uma cultura que incentiva o uso de plantas medicinais. Ao serem questionados sobre o local de aquisição dessas plantas, foi citado principalmente os quintais e vizinhos, isso ocorre devido ao baixo poder aquisitivo que esses 
indivíduos possuem e também pelo fato de estarem inseridos em uma cultura que incentiva a prática do uso de plantas medicinais. Também pode estar associado às limitações biológicas quanto psíquicas, assim eles buscam as plantas em locais próximos e de fácil acesso ${ }^{(17)}$. Estudo realizado também evidenciou que os quintais e jardins são os principais locais de cultivo de plantas medicinais ${ }^{(3)}$.

Em relação ao modo de preparo, como primeira escolha foi relatado a infusão, essa técnica ocorre com a fervura da água, seguido da imersão da planta e abafamento por tempo determinado. Outro modo de preparo citado foi a maceração que consiste no contato da planta medicinal com água, à temperatura ambiente, por tempo determinado ${ }^{(8)}$. Quanto à parte utilizada foi referido principalmente as folhas, que devido serem mais frágeis devem ser preparadas por meio da infusão, resultados coincidentes com a literatura ${ }^{(18)}$.

Ao serem questionados sobre a indicação terapêutica, 36,81\% ( $n=67)$ referiram não indicar por receio de causar malefício, desse modo, infere-se que eles acreditam não fazer mal para si próprio, porém não indicam por medo de toxicidade aos outros. Corroborando com esses resultados pesquisas descrevem que 0 motivo do uso de plantas medicinais remete ao fato de "não fazerem mal à saúde", e que os usuários desconhecem as reações adversas que podem ser desencadeadas ${ }^{(19-20)}$.

Neste estudo foi possível evidenciar que alguns idosos relatam o uso da planta medicinal de forma correta segundo dados da literatura, no entanto quando questionados quanto à toxicidade das mesmas, a afirmação está equivocada. Entre as de uso comum, o Hortelã é citado pela maioria dos idosos, para melhorar a digestão e utilizada em casos de verminoses, resultado este coincidente com a literatura ${ }^{(8)}$, porém citaram que ela pode aumentar o açúcar no sangue. Esse conceito é equivocado, pois entre os diversos efeitos colaterais que podem ser desencadeados pelo uso indiscriminado da Hortelã está a inibição da absorção do ferro, potencialização da ação de fármacos, aumento dos hormônios folículo estimulante e testosterona, além de minimizar efeito antissupressor no organismo, porém não há evidência de causar hiperglicemia ${ }^{(21)}$.

Foi relatado em segundo lugar, que a Cidreira (Cymbopogon citratus (DC) Stapf), utilizada como calmante pode causar "batedeira no coração" e diminuir muito a pressão. A Anvisa reitera que ela apenas pode potencializar o efeito de medicamentos sedativos ${ }^{(9)}$. Um estudo realizado com camundongos verificou que o Cymbopogon citratus (DC) Stapf induz à hipotensão arterial, isso ocorre devido à redução da resistência vascular, e bradicardia provavelmente devido à ativação de receptores muscarínicos cardíacos ${ }^{(22)}$. Outra pesquisa também aborda que a Cidreira possui atividade fungicida, bactericida, antidiarreica, atua como antiinflamatório, anti-espasmódico, hipotensor, anticonvulsivo, analgésico, anti-emético, anti-reumático, antiséptico e tratamento de desordens nervosas e febres e gastrointestinais ${ }^{(23)}$.

Também foi citado "batedeira no coração" ao fazer uso do Guaco (Mikania glomerata Sprengel) e Alecrim (Rosmarinus officinalis L.), porém pesquisa orienta que o uso de Guaco com anti-inflamatórios nãoesteroideis pode interferir na coagulação sanguínea com risco de sangramento em coagulopatias ${ }^{(24)}$. 0 Alecrim é usado para tratamentos cardíacos, hipertensão, insuficiência cardíaca e taquicardia ${ }^{(25)}$.

O Chuchu (Sechium edule (Jacq.) S) popularmente utilizado para diminuir a pressão pode realmente 
causar hipotensão arterial $^{(8)}$, isso ocorre por ser capaz de potencializar o efeito de fármacos utilizados no controle da pressão, desse modo aumenta o risco de hipotensão e predispõe a quedas ${ }^{(22)}$.

Não foram relatados casos de toxicidade nas demais plantas descritas. Entretanto, salientamos para a necessidade de conhecer a finalidade de cada uma delas, devido o relato de que essas duas principais plantas medicinais utilizadas poderiam apresentar esses efeitos colaterais nos idosos, minimizando desse modo o risco do acúmulo de substâncias nocivas ao organismo e por essa prática ser realizada na maioria das vezes sem a orientação de um profissional ${ }^{(20)}$.

Entre as plantas citadas, o Plectranthusbarbatus Andr. (Boldo), Rosmarinus officinalis L. (Alecrim), Citrus aurantium L. subsp. Bergamia (Lima), Malva sylvestris L. (Malva), Mentha Pullegium (Poejo), Maytenus ilicifolia (Schrad.) Planch. (Espinheira-santa), Origanum majorana L. (Manjerona), Artemisia absinthium L. ( Losna), Achillea millefolium L. (Ponta-alívio) e Ruta graveolens L. (Arruda) são indicadas principalmente para tratar afecções do Trato Gastrointestinal ${ }^{(8)}$. Enquanto que a Mikania glomerata Sprengel (Guaco) e Foeniculum vulgare Mill (Erva-doce) atuam como broncodilatadores do Sistema Respiratório ${ }^{(8,25)}$. Já a Baccharis trimera (Less) DC. (Carqueja) e Ruta graveolens L. (Arruda) podem ser utilizadas nas afecções hepáticas, devido ações carminativas ${ }^{(8)}$. A Matricaria chamomilla L. (Camomila) e a Melissa officinalis $L$. (Melissa) agem como sedativos leves, ansiolíticos e antiespasmódicas no Sistema Nervoso Central ${ }^{(22)}$. 0 Sechium edule (Jacq.) S (Chuchu) atua no Sistema Cardiovascular como hipotensor arterial ${ }^{(22)}$, e o Phyllanthus niruri L. (Quebra-pedra) conhecido por suas propriedades litolíticas, atua no Sistema Renal ${ }^{(8)}$.

Os idosos usuários das plantas medicinais conhecem as indicações de determinadas espécies, porém ao ser observado os efeitos colaterais apresentaram na maioria das vezes conceitos divergentes da literatura. Desse modo salienta-se a importância do enfermeiro atuar como um promotor da saúde e ser um facilitador da troca de saberes com esses usuários, incentivando o uso correto.

\section{CONCLUSÃO}

Este estudo evidenciou que os idosos acompanhados pela atenção primária fazem uso de plantas medicinais e que mesmo possuindo o conhecimento empírico sobre o uso destas, as utilizam de forma correta. No entanto, os relatos quanto aos efeitos colaterais e toxicidade das plantas foi bem divergente aos descritos na literatura. Este resultado evidencia a importância de que os profissionais da enfermagem desenvolvam ações com os idosos buscando compreender a prática de uso de plantas medicinais, o cuidado ao uso indiscriminado, forma de preparo, evitando desta forma casos de intoxicação.

Assim, o enfermeiro enquanto educador necessita buscar a capacitação da equipe multiprofissional para atender esses usuários, informando os benefícios que as plantas trazem para o envelhecimento e despertando o interesse para que consigam desvelar os estigmas sociais quanto ao uso de plantas, e incentivar a busca por conhecimento.

O fator limitador desse estudo foi ter sido realizado em um município de pequeno porte, assim os resultados encontrados caracterizam a população em estudo, não podendo ser generalizado. Assim, 
sugerem-se novos estudos que possam abranger uma população maior, verificando as possíveis interações entre o uso de fármacos de uso contínuo e plantas medicinais.

\section{REFERÊNCIAS}

1. Adnan M, Tariq A, Mussarat S, Begum S, AbdElsalam NM, Ullah R. Ethnogynaecological Assessment of Medicinal Plants in Pashtun's Tribal Society. Biomed Res Int [Internet]. 2015 [acesso em: 16 abr. 2017];2015:196475. Disponível em: http://dx.doi.org/10.1155/2015/196475.

2. Mendieta MC, Heck RM, Ceolin S, Souza ADZ, Vargas NRC, Piriz MA, et al. Plantas medicinais indicadas para gripes e resfriados no sul do Brasil. Rev Eletr Enf [Internet]. 2015 [acesso em: 16 abr. 2017];17(3). Disponível em: http://dx.doi.org/10.5216/ree.v17i3.28882.

3. Lima SCS, Arruda GO, Renovato RD, Alvarenga MRM. Representações e usos de plantas medicinais por homens idosos. Rev Lat Am Enfermagem [Internet]. 2012 [acesso em: 16 abr. 2017];20(4):778-86. Disponível em: http://dx.doi.org/10.1590/S0104-11692012000400019.

4. Ministério da Saúde. Programa Nacional de Plantas Medicinais e Fitoterápicos [Internet]. Brasília: Ministério da Saúde, 2009 [acesso em: 16 abr. 2017]. Disponível em:

http://bvsms.saude.gov.br/bvs/publicacoes/programa_nacional_plantas_medicinais fitoterapicos.pdf.

5. Lei no 7.498, de 25 de junho de 1986 (BR) [Internet]. Dispõe sobre a regulamentação do exercício da enfermagem, e dá outras providências. Diário Oficial da União. 26 jun. 1986 [acesso em: 16 abr. 2017]. Disponível em:

http://www.planalto.gov.br/ccivil_03/leis/L7498.htm.

6. Parecer COREN/SC no 003/CT/2010 (BR) [Internet]. Assunto: Prescrição de Plantas Medicinais e Fitoterápicos. Aprovado na 474a Reunião Ordinária dos Conselheiros do Conselho Regional de Enfermagem de Santa Catarina. 28 out. 2010 [acesso em: 16 abr. 2017]. Disponível em: http://www.corensc.gov.br/wp-

content/uploads/2015/07/PARECER-003-2010-CT-Prescrição-de-Plantas-Medicinais-e-Fitoterápicos.pdf.

7. Antonio GD, Tesser CD, Moretti-Pires RO. Contributions of medicinal plants to care and health promotion in primary healthcare. Interface (Botucatu) [Internet]. 2013 [acesso em: 16 abr. 2017];17(46):615-33. Disponível em:

http://dx.doi.org/10.1590/S1414-32832013005000014.

8. Instituto Brasileiro de Geografia e Estatística. População. Projeções e estimativas da população do Brasil e das Unidades da Federação. Projeção da população do Brasil e das Unidades da Federação [Internet]. 2010 [acesso em: 16 abr. 2017]. Disponível em: http://www.ibge.gov.br/apps/populacao/projecao/.

9. Ministério da Saúde. Agência Nacional de Vigilância Sanitária. Formulário Nacional Da Farmacopeia Brasileira [Internet]. 2a ed. Brasília: ANVISA, 2012 [acesso em: 16 abr. 2017]. Disponível em:

http://www.anvisa.gov.br/hotsite/farmacopeiabrasileira/arquivos/2012/FNFB\%202_Revisao_2_COFAR_setembro 20 12 atual.pdf.

10. Agência Nacional de Vigilância Sanitária Brasil. Memento Fitoterápico. Farmacopeia Brasileira [Internet]. $1^{\text {ạ }}$ ed. Brasília: ANVISA, 2016 [acesso em: 16 abr. 2017]. Disponível em:

http://portal.anvisa.gov.br/documents/33832/2909630/Memento+Fitoterapico/a80ec477-bb36-4ae0-b1d2e2461217e06b.

11. Shekarchi M, Hajimehdipoor H, Saeidnia S, Gohari AR, Hamedani MP. Comparative study of rosmarinic acid content in some plants of Labiatae family. Pharmacogn Mag [Internet]. 2012 [acesso em: 16 abr. 2017];8(29):37-41. Disponível em: http://dx.doi.org/10.4103/0973-1296.93316.

12. Carvalho TB, Lemos ICS, Sales VS, Figueiredo FRSDN, Rodrigues CKS, Kerntopf MR. Papel dos Idosos no Contexto do Uso de Plantas Medicinais: Contribuições à Medicina Tradicional. Ensaios e Ciência: Ciências Biológicas, Agrárias e da Saúde [Internet]. 2015 [acesso em: 16 abr. 2017];19(1):38-41. Disponível em:

http://www.pgsskroton.com.br/seer/index.php/ensaioeciencia/article/view/3014.

13. Almeida AV, Tavares Mafra SC, Silva EP, Kanso S. A Feminização da Velhice: em foco as características socioeconômicas, pessoais e familiares das idosas e o risco social. Textos Context (Porto Alegre) [Internet]. 2015 [acesso em: 16 abr. 2017];14(1):115-31. Disponível em: http://dx.doi.org/10.15448/1677-9509.2015.1.19830. 14. Vasconcelos MKP, Lima ARA, Barbieri RL, Heck RM. Medicinal plants used by octogenarians and nonagenarians 
from a small village in Rio Grande/RS, Brazil. Revista de enfermagem UFPE on line [Internet]. 2011 [acesso em: 16 abr. 2017];5(6):1329-36. Disponível em: https://periodicos.ufpe.br/revistas/revistaenfermagem/article/view/6799. 15. Ceolin T, Heck RM, Barbieri RL, Schwartz E, Muniz RM, Pillon CN. Medicinal plants: knowledge transmission in families of ecological farmers in souther Rio Grande do Sul. Rev. esc. enferm. USP [Internet]. 2011 [acesso em: 16 abr. 2017];45(1):47-54. Disponível em: http://dx.doi.org/10.1590/S0080-62342011000100007.

16. Colet C, Cavalheiro C, Dal-Molin G, Cavinatto A, Schiavo M, Schwambach K, et al. Uso de plantas medicinais por usuários do serviço público de saúde do município de ljuí/RS. Revista Brasileira de Medicina de Família e Comunidade [Internet]. 2015 [acesso em: 16 abr. 2017];10(36). Disponível em: http://dx.doi.org/10.5712/rbmfc10(36)930. 17. Oliveira ER, Menini Neto L. Levantamento etnobotânico de plantas medicinais utilizadas pelos moradores do povoado de Manejo, Lima Duarte - MG. Rev. bras. plantas med. [Internet]. 2012 [acesso em: 16 abr. 2017];14(2):31120. Disponível em: http://dx.doi.org/10.1590/S1516-05722012000200010.

18. Silva LE, Quadros DA, Maria Neto AJ. Estudo etnobotânico e etnofarmacológico de plantas medicinais utilizadas na região de Matinhos - PR. Ciência e Natura [Internet]. 2015 [acesso em: 16 abr. 2017];37(2):266-76. Disponível em: http://dx.doi.org/10.5902/2179460X15473.

19. Ângelo T, Ribeiro CC. Utilização de plantas medicinais e medicamentos fitoterápicos por idosos. Revista Ciência e Desenvolvimento [Internet]. 2014 [acesso em: 16 abr. 2017];7(1):18-31. Disponível em:

http://srv02.fainor.com.br/revista/index.php/memorias/article/view/246.

20. Carneiro FM, Silva MJP, Borges LL, Albernaz LC, Costa JDP. Tendências dos estudos com plantas medicinais no Brasil. Revista Sapiência: sociedade, saberes e práticas educacionais [Internet]. 2015 [acesso em: 16 abr. 2017];3(2):44-75. Disponível em: http://www.revista.ueg.br/index.php/sapiencia/article/view/2954.

21. Felten RD, Magnus K, Santos L, Souza AH. Interações medicamentosas associadas a fitoterápicos fornecidos pelo Sistema Único de Saúde. Inova Saúde [Internet]. 2015 [acesso em: 16 abr. 2017];4(1):47-64. Disponível em: http://dx.doi.org/10.18616/is.v4i1.1909.

22. Moreira FV., Bastos JFA, Blank AF, Alves PB, Santos MRV. Chemical composition and cardiovascular effects induced by the essential oil of Cymbopogon citratus DC. Stapf, Poaceae, in rats. Rev Bras Farmacogn [Internet]. 2010 [acesso em: 16 abr. 2017];20(6):904-9. Disponível em: http://dx.doi.org/10.1590/S0102-695X2010005000012.

23. Shah G, Shri R, Panchal V, Sharma N, Singh B, Mann AS. Scientific basis for the therapeutic use of Cymbopogon citratus, stapf (Lemon grass). J Adv Pharm Technol Res [Internet]. 2011 [acesso em: 16 abr. 2017];2(1):3-8. Disponível em: http://dx.doi.org/10.4103/2231-4040.79796.

24. Tsai HH, Lin HW, Simon Pickard A, Tsai HY, Mahady GB. Evaluation of documented drug interactions and contraindications associated with herbs and dietary supplements: a systematic literature review. Int J Clin Pract [Internet]. 2012 [acesso em: 16 abr. 2017];66(11):1056-78. Disponível em: http://dx.doi.org/10.1111/j.17421241.2012.03008.x.

25. Afonso MS, Sant'Ana LS, Mancini-Filho J. Interação entre antioxidantes naturais e espécies reativas do oxigênio nas doenças cardiovasculares: perspectivas para a contribuição do alecrim (Rosmarinus officinalis L.). Nutrire: Revista da Sociedade Brasileira de Alimentação e Nutrição [Internet]. 2010 [acesso em: 16 abr. 2017];35(1):129-48. Disponível em: $\underline{\text { http://sban.cloudpainel.com.br/files/revistas_publicacoes/277.pdf. }}$ 